\title{
Deafferented Adult Rod Bipolar Cells Create New Synapses with Photoreceptors to Restore Vision
}

\author{
CCorinne Beier, ${ }^{1}$ Anahit Hovhannisyan, ${ }^{2}$ 'Sydney Weiser, ${ }^{2}$ Jennifer Kung, ${ }^{3}$ Seungjun Lee, ${ }^{3}$ Dae Yeong Lee, ${ }^{3}$ \\ Philip Huie, ${ }^{3,4}$ Roopa Dalal, ${ }^{4}$ Daniel Palanker, ${ }^{3,4}$ and Alexander Sher ${ }^{2}$ \\ ${ }^{1}$ Electrical Engineering and ${ }^{2}$ Santa Cruz Institute for Particle Physics, University of California, Santa Cruz, California 95064, and ${ }^{3}$ Ophthalmology and \\ ${ }^{4}$ Hansen Experimental Physics Laboratory, Stanford University, Stanford, California 94305
}

\begin{abstract}
Upon degeneration of photoreceptors in the adult retina, interneurons, including bipolar cells, exhibit a plastic response leading to their aberrant rewiring. Photoreceptor reintroduction has been suggested as a potential approach to sight restoration, but the ability of deafferented bipolar cells to establish functional synapses with photoreceptors is poorly understood. Here we use photocoagulation to selectively destroy photoreceptors in adult rabbits while preserving the inner retina. We find that rods and cones shift into the ablation zone over several weeks, reducing the blind spot at scotopic and photopic luminances. During recovery, rod and cone bipolar cells exhibit markedly different responses to deafferentation. Rod bipolar cells extend their dendrites to form new synapses with healthy photoreceptors outside the lesion, thereby restoring visual function in the deafferented retina. Secretagogin-positive cone bipolar cells did not exhibit such obvious dendritic restructuring. These findings are encouraging to the idea of photoreceptor reintroduction for vision restoration in patients blinded by retinal degeneration. At the same time, they draw attention to the postsynaptic side of photoreceptor reintroduction; various bipolar cell types, representing different visual pathways, vary in their response to the photoreceptor loss and in their consequent dendritic restructuring.
\end{abstract}

Key words: dendrite restructuring; photoreceptor; plasticity; retina; retinal bipolar cell; synapse formation

Significance Statement

Loss of photoreceptors during retinal degeneration results in permanent visual impairment. Strategies for vision restoration based on the reintroduction of photoreceptors inherently rely on the ability of the remaining retinal neurons to correctly synapse with new photoreceptors. We show that deafferented bipolar cells in the adult mammalian retina can reconnect to rods and cones and restore retinal sensitivity at scotopic and photopic luminances. Rod bipolar cells extend their dendrites to form new synapses with healthy rod photoreceptors. These findings support the idea that bipolar cells might be able to synapse with reintroduced photoreceptors, thereby restoring vision in patients blinded by retinal degeneration.

\section{Introduction}

Normally, the adult mammalian retina is a stable neural network, but it exhibits structural and synaptic plasticity in response to loss

Received Aug. 12, 2016; revised March 24, 2017; accepted March 27, 2017.

Author contributions: C.B., D.P., and A.S. designed research; C.B., A.H., J.K., S.L., D.Y.L., P.H., R.D., and A.S. performed research; C.B., A.H., S.W., and A.S. analyzed data; C.B. and A.S. wrote the paper.

This work was supported by Burroughs Wellcome Fund Career Award at the Scientific Interface, Pew Charitable Trusts Scholarship in the Biomedical Sciences, National Institutes of Health Grant EY023020-01 to A.S., and Fight for Sight Summer Fellowship to C.B. We thank Stephen Massey for providing the mGluR6 antibody; Christopher Whitaker and Stephen Massey for providing cell-fill photographs for dendritic reach measurements; Ben Abrams for microscopy assistance and maintaining microscopy centers; Sergei Kachiguine for multielectrode recording system support; and Steven DeVries, David Feldheim, and Jena Yamada for helpful comments.

The authors declare no competing financial interests.

Correspondence should be addressed to either Dr. Corinne Beier or Dr. Alexander Sher, University of California, Santa Cruz Santa Cruz Institute for Particle Physics, Natural Sciences 2, 1156 High Street, Room 337, Santa Cruz, CA 95064.E-mail: cbeier@ucsc.edu or sashake3@ucsc.edu.

DOI:10.1523/JNEUROSCI.2570-16.2017

Copyright $\odot 2017$ the authors $\quad 0270-6474 / 17 / 374635-10 \$ 15.00 / 0$ of photoreceptors during injury or disease. The resulting deafferentation of the inner retinal neurons disturbs the organized retinal structure, leading to abnormal circuit connectivity and function (Marc et al., 2003; Stasheff et al., 2011; D'Orazi et al., 2014). One approach to restore vision in patients blinded by the loss of photoreceptors is based on the reintroduction of healthy photoreceptors into diseased retina (MacLaren et al., 2006; Singh and MacLaren, 2011; Pearson, 2014). The success of this approach depends on the ability of the remaining retinal cells to form new synapses with the introduced photoreceptors while maintaining normal connectivity patterns in the inner retina.

Previous studies have shown that not all changes in the retina after injury are disruptive. In particular, local and selective ablation of photoreceptors leads to the shift of the surrounding healthy photoreceptors into the lesioned area (Busch et al., 1999; Paulus et al., 2008; Lavinsky et al., 2013; Strazzeri et al., 2014). Furthermore, it was shown that the shifting photoreceptors pro- 
vide inputs to the retinal circuitry and that the inner retinal neurons in the lesioned area become responsive to light (Sher et al., 2013). However, it is unclear how the shifting photoreceptors integrate into the deafferented portion of the retina, and whether the new connectivity is similar to that in the healthy retina.

We use short-pulse laser photocoagulation to selectively ablate a patch of photoreceptors in adult rabbits, leaving the bipolar cells intact but deafferented. Using immunohistochemistry to visualize the photoreceptor and bipolar cells at different times after ablation and multielectrode array recordings to monitor visual function, we find that the adult rabbit retina is capable of synaptogenesis while avoiding some of the deleterious structural changes associated with retinal degeneration. We observed dramatic morphological rearrangement of the dendrites from rod bipolar cells, resulting in their targeted expansion toward healthy photoreceptors. Extended rod bipolar cell dendrites make synaptic contacts with new rod afferents, thereby restoring vision in the adult mammalian retina.

\section{Materials and Methods}

Selective photocoagulation. Adult Dutch Belted rabbits were used in accordance with the Association for Research in Vision and Ophthalmology Statement Regarding the Use of Animals in Ophthalmic and Vision Research after approval from the Stanford University Animal Institutional Review Board. Rabbits of either sex were anesthetized using ketamine hydrochloride $(35 \mathrm{mg} / \mathrm{kg}$ rabbit, i.m.) and xylazine $(5 \mathrm{mg} / \mathrm{kg}$ rabbit, i.m.) $15 \mathrm{~min}$ before the procedure. A single drop of both $1 \%$ tropicamide and $2.5 \%$ phenylephrine hydrochloride was applied to each eye to dilate the pupil. Lesions were applied to the retina with a scanning laser (PASCAL, $532 \mathrm{~nm}$ ) using custom scanning software. A laser beam of $100 \mu \mathrm{m}$ in diameter was scanned twice with $100 \mathrm{~ms}$ delay over $1.5 \mathrm{~mm}$ length of the retina at $1.6 \mathrm{~m} / \mathrm{s}$ scanning velocity and power of $2.0-2.2 \mathrm{~W}$. The 200- and 300- $\mu \mathrm{m}$-wide lesions were created by overlapping multiple $100-\mu \mathrm{m}$-wide scans, such that the overlap was equal to half the beam diameter. Therefore, a $200-\mu \mathrm{m}$-wide lesion was made with 3 overlapping $100-\mu \mathrm{m}$-wide lines, and a 300- $\mu \mathrm{m}$-wide lesion required 5 lines. Rabbits underwent this procedure twice to place acute (3- to 16-d-old) lesions near ( $\sim 400 \mu \mathrm{m}$ from) older (1- to 4-month-old) lesions.

Electrophysiology and analysis. Lesioned eyes were enucleated under terminal anesthesia in dim red light. The anterior portion of the eye, the lens, and the vitreous were removed from the eye cup. The eye cup, with retina still attached to retinal pigment epithelium and choroid, was kept in oxygenated Ames' solution (Sigma-Aldrich) heated to $32^{\circ} \mathrm{C}$ and kept in the dark, except to remove pieces of retina for placement on the microelectrode array. A $4 \times 4 \mathrm{~mm}^{2}$ piece of retina containing four lesions (two acute and two older lesions) was isolated from the choroid under an infrared microscope and placed ganglion cell side down onto the array $\left(1.7 \mathrm{~mm}^{2}\right.$ area $)$ such that two or three lesions overlapped with the electrodes. Peanut agglutinin $568 \mathrm{~nm}$ (1:100 in Ames' solution, Invitrogen) was added to the array chamber before the retina piece was oriented on the array. During the experiment, the retina was perfused with fresh oxygenated Ames' solution at $32.4^{\circ} \mathrm{C}$. Stimuli were presented to the retina by a CRT computer monitor focused through the microscope objective onto the photoreceptor layer. After presenting stimuli, we imaged the relative positions of the array and stimulus, as well as the photoreceptor outer segments (visualized with peanut agglutinin), so that we could map lesion locations to the presented stimulus. For scotopic recordings, retinal pieces were dissected using only infrared illumination. The retina was then presented a light stimulus at $5-13 \mathrm{Rh}^{*} / \mathrm{rod} / \mathrm{s}$, using neutral density filters to reduce the light intensity. A photopic stimulus (5400 $\mathrm{Rh}^{\star} / \mathrm{rod} / \mathrm{s}$ ) was presented immediately afterward to provide direct comparison of scotopic and photopic responses from the same retinal preparation. After the experiment, the retina was removed from the array and prepared for immunohistochemistry.

Typically, spike trains of hundreds of individual retinal ganglion cells (RGCs) were identified from a single piece of retina using custom software that distinguishes action potentials of individual cells through the unique voltage signals recorded on the electrodes (Litke et al., 2004; Field et al., 2007; Sher and DeVries, 2012). Retinal ganglion cells were characterized by their spike-triggered average (STA) response to binary white noise stimulus (checkerboard-like stimulus: 45 or $90 \mu \mathrm{m}$ checkers, flickering independently at 20,30, or $60 \mathrm{~Hz}$ ). Retinal sensitivity over space was calculated by adding the STA spatial sensitivity profiles of all the detected RGCs that had a 2.7 signal-to-noise ratio in their STAs.

Immunohistochemistry. Pieces of retinal tissue were separated from the choroid and placed in 4\% PFA, pH 7.4, for $60 \mathrm{~min}$ at room temperature. Retina was washed 6 times for $30 \mathrm{~min}$ in a modified PBS (mPBS) solution $\left(0.1 \mathrm{M}, \mathrm{pH} 7.4,0.1 \% \mathrm{NaN}_{3}, 0.5 \%\right.$ Triton $\left.\mathrm{X}-100\right)$ at room temperature, blocked for $2 \mathrm{~d}$ in mPBS with $3 \%$ donkey serum at $4^{\circ} \mathrm{C}$, and incubated in primary and then secondary antibodies for 5 and $2 \mathrm{~d}$, respectively, in $1 \%$ donkey serum in $\mathrm{mPBS}$ at $4 \mathrm{C}$. Retinas were washed 4 times for $30 \mathrm{~min}$ in $\mathrm{mPBS}$ before being mounted onto slides, with DAPI $(0.2 \mu \mathrm{g} / \mathrm{ml}$ SigmaAldrich) added during the last wash. We used the following primary antibodies: mouse anti-protein kinase $\mathrm{C} \alpha(\mathrm{PKC} \alpha)(1: 100$, Santa Cruz Biotechnology, sc-8393), rabbit anti-PKC $\alpha$ (1:100, Santa Cruz Biotechnology, sc-208), mouse anti-C-terminal binding protein 2 (CtBP2; 1:400, BD Biosciences, 612044), goat anti-CtBP2 (1:100, Santa Cruz Biotechnology, sc-5966), rabbit anti-metabolic glutamate receptor 6 (mGluR6; 1:1000, a gift from Stephen Massey) (Pan and Massey, 2007), and rabbit anti-secretagogin (1:400, Sigma-Aldrich, HPA006641). The following secondary antibodies (1:1000, Invitrogen) were paired with the appropriate primary antibodies: donkey anti-goat $555 \mathrm{~nm}$, donkey anti-mouse 488 or $647 \mathrm{~nm}$, and donkey anti-rabbit 488 or $647 \mathrm{~nm}$. Peanut agglutinin $568 \mathrm{~nm}$ (1:200) was also sometimes added during the secondary incubation period. Retinas were mounted with Vectashield (H-1000; Vector Laboratories).

Imaging and image preparation. Lesions were imaged on a Leica SP5 confocal microscope with oil-immersion lenses $(40 \times$ NA 1.25 or $63 \times$ NA 1.4). Voxel size was set by $532 \mathrm{~nm}$ Nyquist values, and each optical plane was imaged 3 or 4 times. ImageJ software (National Institutes of Health) was used to generate $z$ projections and cross sections from $z$ stacks.

Image analyses. For most calculations, measurements were first made in ImageJ by creating regions of interest and then transferring these data to MATLAB (The MathWorks) for further processing.

To assess the lesion closure, a mask for the $z$ projection of the outer plexiform layer (OPL) ribbons was created in MATLAB, and the area lacking ribbons was used to determine an equivalent width of the lesion given that the lesion spanned the entire length of the image (area of mask $=$ image length $\times$ equivalent width of lesion). The same calculation was made for the combined STAs of lesioned retinas to calculate functional closure.

The data on soma location, number of dendrites, dendritic reach, and rod bipolar cell to cone pedicle interactions were first collected on $z$ stacks in Image and then analyzed in MATLAB. Definitions for dendritic reach and rod bipolar to cone pedicle interactions follow.

For each dendritic branch, the dendritic reach was measured as a straight-line length from the base of the dendrite at the cell body out to the dendritic terminal farthest from the cell body. PKC $\alpha$-positive thickened rod bipolar cell dendrites were measured to the extent that they could no longer be distinguished from surrounding dendrites. These measurements are therefore an underestimation of the thickened dendrite's reach. Because all the rod bipolar cells are stained with PKC $\alpha$, the overlap of their dendritic fields prevented us from measuring the length of individual dendrites in healthy cells. Instead, we measured the dendritic reach of four healthy individually filled rod bipolar cells from mid-inferior rabbit retina (provided by Christopher Whitaker and Stephen Massey, cell-fill photographs not shown). The dendritic reach quantifies the photoreceptor sampling range of a single dendritic branch much the same way the dendritic field area quantifies the photoreceptor sampling range of an entire bipolar cell. To scale the dendritic fields of the filled healthy cells to the $1200 \mu \mathrm{m}^{2}$ dendritic field area of the far peripheral retina, a scaling factor, given by $\left(1200 \mu \mathrm{m}^{2} /\right.$ mean dendritic field area of filled cells $)^{1 / 2}$, was applied to each dendritic reach. The mean dendritic field area of the filled healthy cells was $636 \mu \mathrm{m}^{2}$.

Healthy rod bipolar cell dendrites, scaled to emulate cells in the far peripheral retina (see previous paragraph) did not reach beyond $28 \mu \mathrm{m}$ 
from the cell body ( 0 of 32 dendrites). The frequency of thick restructured rod bipolar cell dendrites reaching beyond $28 \mu \mathrm{m}$ from their cell body to their first synaptic contact was measured to be $6 / 41$ ( 6 of 41 cells located inside 4-month-old lesion, $28 \mu \mathrm{m}$ or further from the nearest photoreceptor synaptic ribbon). We calculated the probability of these two observations coming from the same underlying distribution using Monte-Carlo simulation. In particular, we simulated $10^{10}$ results of the binomial experiment where 41 attempts are made with the underlying success probability of $6 / 41$, yielding the number of successes, R. For each $\mathrm{R}$, we simulated a binomial experiment with 32 attempts and underlying success rate of $\mathrm{R} / 41$, yielding the number of successes $\mathrm{R} 1$. The $p$ value was calculated as the ratio of the number of times $\mathrm{R} 1$ was equal to 0 in the $10^{10}$ attempts. It was found to be: $p=0.030\left(\operatorname{SEM}=10^{-6}\right)$. The uncertainty was estimated by subdividing the $10^{10}$ attempts into $10^{6}$ groups of 10,000 attempts each, calculating the $p$ value for each group and then calculating the SE of the $p$ value mean.

For each primary dendrite, the dendritic projection was measured as the angle the dendrite left the cell body of secretagogin- and PKC $\alpha$ positive cells relative to the lesion edge. Some secretagogin-positive cells sent a dendritic stalk vertically toward the OPL before branching. If a cell had a vertical stalk, the dendrites branching off the stalk were considered the primary dendrites and the angles at which they branched from the stalk were measured. If a dendrite between two cells appeared to originate from both somas, then it was measured for both cells. A vector sum of each cell's dendrites was created by summing the unit length projection vectors of each measured primary dendrite. The directionality index (DI) for each cell was defined as DI $=($ exit - enter $) /($ exit + enter $)$ where exit $=$ number of dendrites projected away from lesion center and enter $=$ number of dendrites projected toward lesion center.

Rod bipolar cell and cone pedicle interactions were classified into three categories while viewing a $z$ stack with PKC $\alpha$, CtBP2, and mGluR6 staining in ImageJ. A cone pedicle was marked "approached" if a rod bipolar cell dendrite terminated within the cone pedicle area (identified by mGluR6 and ribbon morphology) without colocalizing with a rod spherule (identified by a mGluR6 doublet). If a dendrite passed through a cone pedicle to make contact with a rod spherule, the cone was marked "ignored." A cone pedicle was "avoided" if no rod bipolar cell dendrites approached or passed through the cone pedicle. Examples of the three types of interaction between cone pedicle and rod bipolar cell dendrites can be found in Figure 4C. Cone pedicles that could not be categorized due to a very bright rod bipolar cell body obscuring possible approaches were removed from the analysis.

Sprouting events were counted in lesions of various ages using equally sized $(50 \mu \mathrm{m})$ cross sections from confocal stacks.

\section{Results}

\section{Photopic and scotopic visual sensitivity is restored after photoreceptor ablation}

Using a rapidly scanning laser, we selectively coagulated a rectangular patch of photoreceptors in the mid-inferior region of the adult rabbit retina, leaving the inner nuclear layer (INL) intact (Paulus et al., 2011; Lorach et al., 2015). The 1.5-mm-long line lesion patterns of $0.1,0.2$, and $0.3 \mathrm{~mm}$ in width were examined $3 \mathrm{~d}$ to 4 months after procedure. In some cases, acute lesions $(<16 \mathrm{~d})$ were placed next to older lesions $(1,2$, and 4 months) in the same retina to provide a reference for structural and functional changes between younger and older lesions.

Examination of the retinas using immunohistochemistry shows that healthy photoreceptors adjacent to the lesion shift into the damaged zone over time. Staining with peanut agglutinin to identify cone outer segments and a rabbit anti-PKC $\alpha$ antibody that outlines rod outer segments shows that the gap in both rod and cone outer segments narrows over time after the injury (Fig. $1 A$ ). This finding is consistent with previous reports (Busch et al., 1999; Paulus et al., 2008, 2011; Lavinsky et al., 2013; Sher et al., 2013; Strazzeri et al., 2014). Two mechanisms could account for this filling in: photoreceptor outer segments could lean into the lesion, leaving their pedicles and spherules behind, or the entire photoreceptor could shift into the lesion. To distinguish between these possibilities, we imaged the horseshoe-shaped ribbon structures found at the cone pedicle and rod spherule synapses using an antibody to CtBP2, which are found in the cells' termini. We find that the width of the gap in ribbon coverage also narrows over time (between 3 and 120 d, Student's $t$ test, $p<0.02$ ), with most ribbon movement occurring within the first month of ablation (see an example in Fig. $1 A$ and the average data based on 151 lesions in 4 rabbits in Fig. $1 B$ ). After $30 \mathrm{~d}$, there was no additional significant closure of the lesions (Student's $t$ test, $p>0.15$ ). In 1 of 5 rabbits (31 lesions), we observed no statistically significant change (Student's $t$ test, $p>0.25$ ) in the ribbon coverage gap (Fig. 1B, gray lines). This likely reflects variability observed in the initial damage and healing dynamics between animals. A smaller gap in ribbon coverage remains 4 months after lesioning, even in the areas where the photoreceptor outer segments filled in the initial damage zone (Fig. 1A). Therefore, we conclude that the entire photoreceptor shifts into the lesion and photoreceptor outer segments lean further inward. Both cone and rod ribbon structures (dimmer clustered ribbons and bright horseshoe-shaped ribbons, respectively) are present inside the initial lesion boundaries, indicating that both cone pedicles and rod spherules can shift into the lesion (Fig. 1A).

To determine whether the shifting photoreceptors convey information to the retina, we used a multielectrode array (Litke et al., 2004) to record responses of the RGCs located within and outside the lesions. Previous work using 200 - $\mu \mathrm{m}$-diameter spot lesions showed that shifting photoreceptors restored visual sensitivity to the blinded area under photopic conditions, which predominantly measures cone function (Sher et al., 2013). Here we measure rod and cone photoreceptor-mediated responses separately. We used binary spatiotemporal white noise stimuli at scotopic and photopic mean luminances (5-13 and $5400 \mathrm{Rh}^{\star}$ I $\mathrm{rod} / \mathrm{s}$, respectively) to determine the extent of recovery in both rod and cone pathways. The RGC's spike-triggered average response to a white noise stimulus measures the cell's spatiotemporal receptive field and reveals its spatial sensitivity profile (Chichilnisky, 2001). Combining the receptive fields of all recorded RGCs from a single piece of retina with two 1-week-old line lesions reveals two distinct blind spots under both photopic and scotopic stimulation conditions (Fig. 1C). This confirms that laser photocoagulation leads to loss of visual sensitivity in RGC receptive fields. For all three lesion widths (100, 200, and 300 $\mu \mathrm{m}$ ), the blind spot narrows over time (between 7 and $120 \mathrm{~d}$, Student's $t$ test, $p<0.03$ ), as observed across 28 lesions in 7 rabbits (Fig. 1C,D). We do not see significant closure in lesions after $30 \mathrm{~d}$ (Student's $t$ test, $p>0.09$ ), which resembles the dynamics of the shifting ribbons. Furthermore, the functional recovery mediated by cone and rod photoreceptors is matched, as shown by a subset of experiments with scotopic and photopic data ( $n=12$ lesions, 5 rabbits) (Fig. $1 E$ ).

These results demonstrate that cone and rod photoreceptors shift into the lesioned area and that their respective pedicles and spherules have functional connections with bipolar cells.

\section{Deafferented rod bipolar cells extend their dendrites toward photoreceptors}

To understand how dendritic fields of bipolar cells change in response to local photoreceptor loss, we visualized rod and cone bipolar cells, as well as their presynaptic and postsynaptic structures, using immunohistochemistry and confocal microscopy on flat mounted retinas. The synapses between rod spherules and 
A

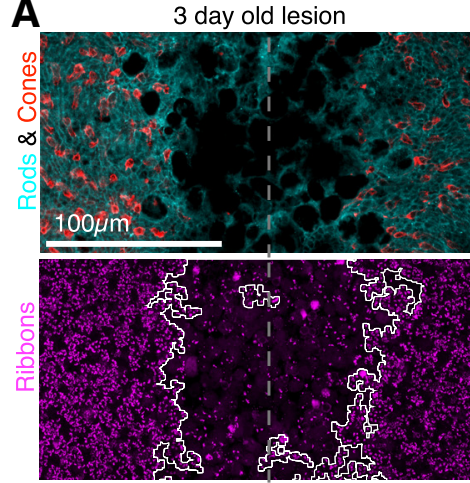

C

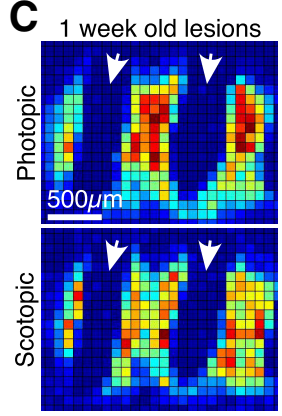

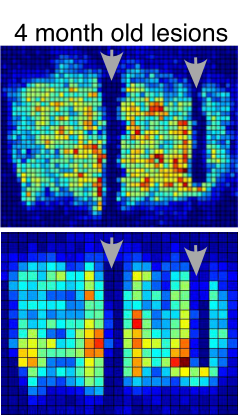

4 month old lesion

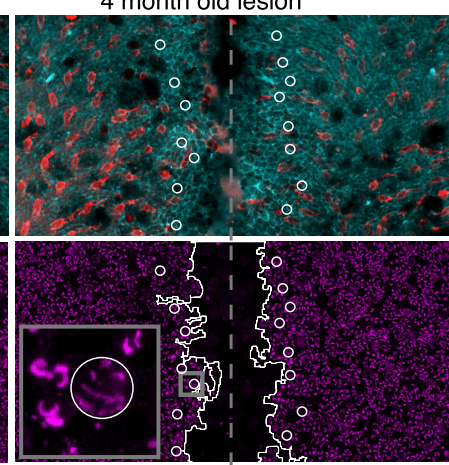

$D_{500}$

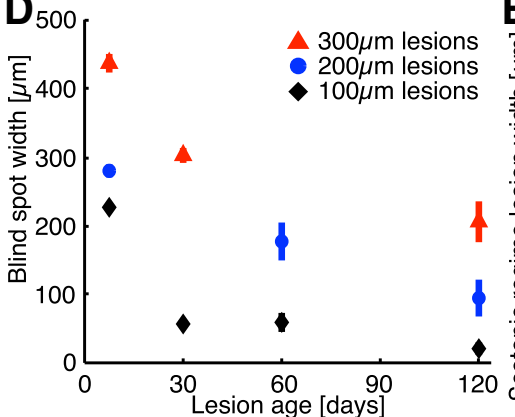

B
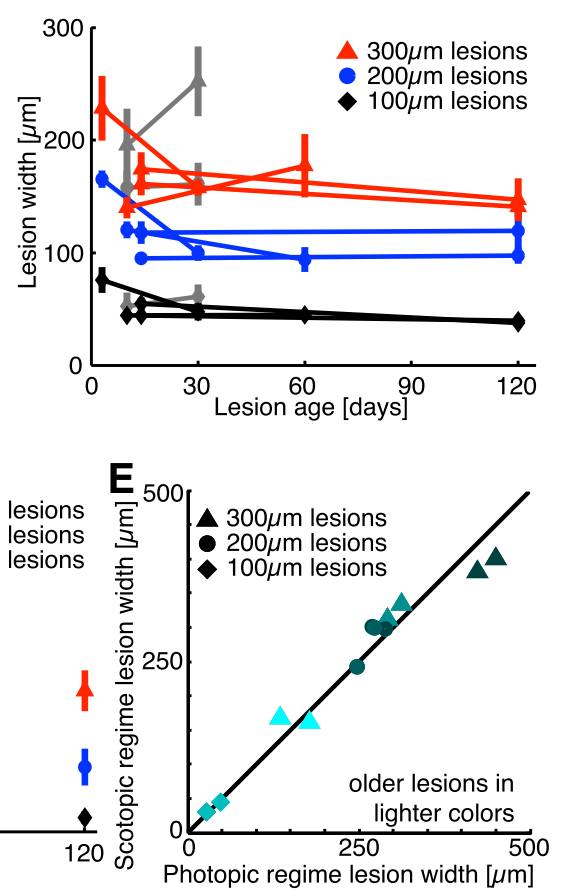

Figure 1. Photoreceptor outer segments and their synapses shift into lesions over time and restore visual sensitivity in the rod and cone pathways. $\boldsymbol{A}$, Rod and cone outer segments at the edges of a 3-d-old and 4-month-old, 100- $\mu \mathrm{m}$-wide lesion. Dashed gray line indicates lesion center. Ribbons (in the OPL) are visible at the lesion edges. Lesion edges were defined as the solid white outlines, calculated with custom software. Both cone (circled) and rod ribbons are found inside the former lesion edges. $\boldsymbol{B}$, Lesion width over time, as measured by lack of ribbon coverage (calculated from lesion outlines in $\boldsymbol{A}$ ). Widths are reported for 100-, 200-, and 300- $\mu \mathrm{m}$-wide $\times 1.5$-mm-long laser scanned areas. Lines connect acute (3-16 d) and older (1, 2, or $4 \mathrm{month}$ ) lesions placed in the same rabbit. One of five rabbits did not show lesion closure (grayed out, Student's $t$ test, $p>0.25$ ). Data are mean \pm SEM. C, Examples of visual sensitivity plots, obtained from spike-triggered average sensitivity profiles, in retinas with $300 \mu \mathrm{m}$ lesions. Gaps in visual sensitivity in both the photopic and scotopic regime are much wider in 1-week-old lesions (white arrows) than in 4-month-old lesions (gray arrows). Pixel size in these maps is defined by the stimulus pixel size. All panels are scaled equally. D, Lesion width as measured by lack of visual sensitivity in the photopic regime over time. Data are mean \pm SEM. $\boldsymbol{E}$, Comparison of visual sensitivity lesion widths in the photopic and scotopic regime ( $n=12$ lesions).

rod bipolar cells were identified using antibodies against $\mathrm{PKC} \alpha$ to stain the rod bipolar cell, mGluR6 to stain the rod bipolar cell glutamate receptor, and CtBP2 to stain synaptic ribbons (Young and Vaney, 1991; Vardi et al., 2000; tom Dieck et al., 2005). In healthy rod bipolar cells, dendritic tips invade the rod spherule to make a synaptic contact (Dacheux and Raviola, 1986). Glutamate receptor mGluR6 is localized to the dendritic tip region within the bipolar cells (Vardi et al., 2000) and appears as a doublet that represents two rod bipolar cells contacting a single rod spherule (Li et al., 2004) (Fig. 2A, insets).

Deafferented rod bipolar cells lose their dendritic tips and most mGluR6 expression within days of the photoreceptor ablation, without altering the structure of their dendritic trees (Fig. $2 A$ ). Two weeks after ablation, the finer dendritic processes start to disappear, and a few bipolar cells restructure their dendrites to have thickened processes directed toward the healthy photoreceptors at the lesion edge (Fig. 2A). Over time, deafferented rod bipolar cells significantly restructure their dendritic trees, such that most dendritic branches are eliminated (Fig. 2B). The remaining dendritic branches, which appear thickened, extend toward the edge of the lesion (Fig. 2C-E). The thickened dendrites terminate in the ribbon-rich areas of the OPL and have dendritic tips that colocalize with mGluR6 and rod ribbons (Fig. 2D).

On- and off-cone bipolar cell dendrites, visualized with an antibody against secretagogin (Puthussery et al., 2010), do not undergo the obvious changes we observe in rod bipolar cells. While the dendritic network of the cone bipolar cells is disturbed within the lesion, the mean number of major dendritic branches remains the same inside and outside the lesion at all ages
(Student's $t$ test, $p>0.12$; Fig. $2 F, G$ ). Rare examples of a thick process extending toward the healthy photoreceptors are an exception rather than a rule (data not shown).

To compare the response to deafferentation between the rod bipolar and secretagogin-positive cells, we analyzed data from four lesions immunostained at four time points after photocoagulation (Fig. 3A). Both rod bipolar cells and secretagogin-positive cone bipolar cells were labeled in each of the four retinal pieces, providing for the direct comparison. We measured the projection angle of all primary dendrites extending from each cell inside and outside of each of these lesions. The dendritic projections of each cell's dendrites were then added vectorially to obtain a single vector representing the dendritic projection of each cell (Fig. 3B). In this vector sum, each dendrite was weighted equally, regardless of its total length or thickness. Dendritic projections of rod bipolar cells show a bias toward the lesion edge (Fig. $3 C$ ), which correlates with the preferred direction of the thickened dendrites (Fig. 2E). However, the distribution of the secretagogin-positive cells' dendritic projections did not show such an obvious bias (Fig. 3C). To quantify the difference between the two cell types, we calculated the DI of each cell (see Materials and Methods). Cells with no directional preference in their primary dendrites had a DI value of 0 . A DI value of 1 or -1 meant that a cell directed all of its dendrites away from or toward the lesion center, respectively. The DI index was calculated for each of the lesions in Figure $3 A$, and separately for rod bipolar and secretagoginpositive cone bipolar cells located inside and outside the lesion. Secretagogin-positive cells inside the lesion have the same DI as those outside the lesion, confirming that their dendrites do not re- 


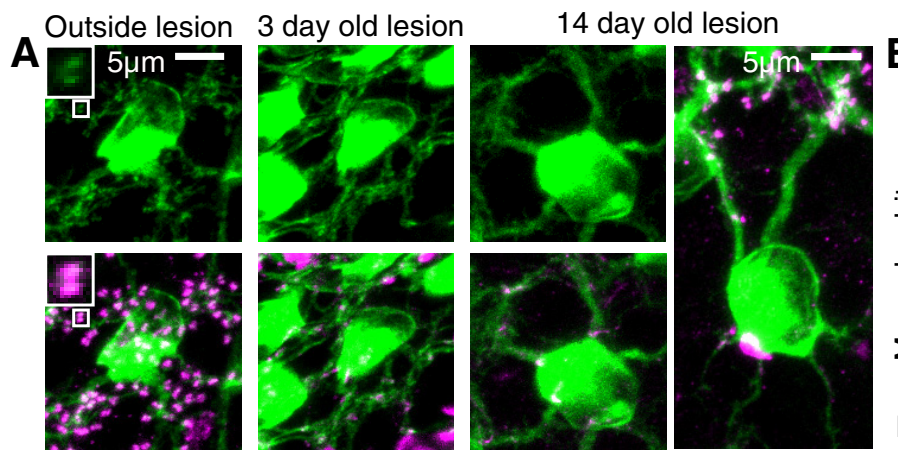

C

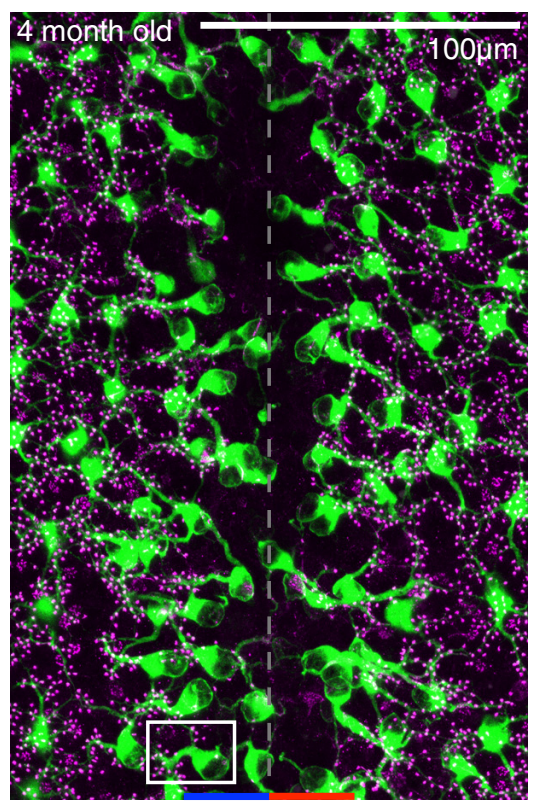

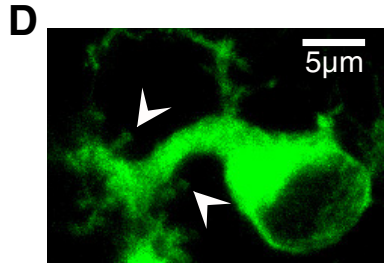

E

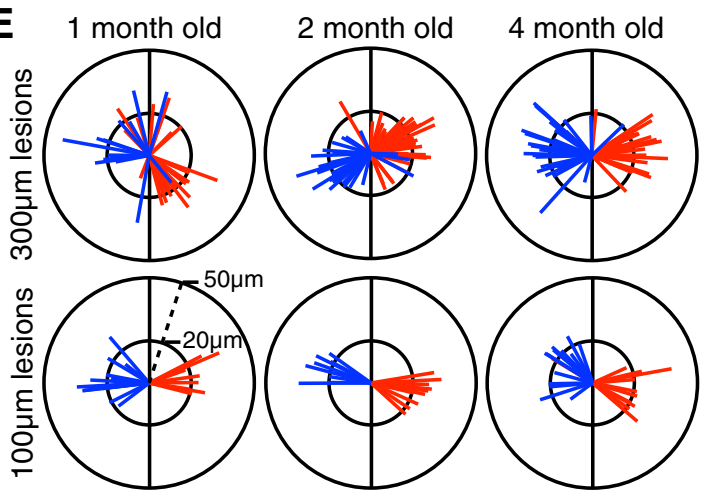

F
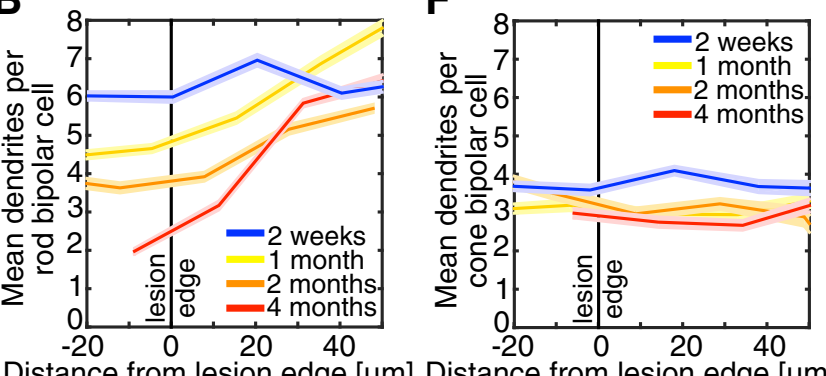

G
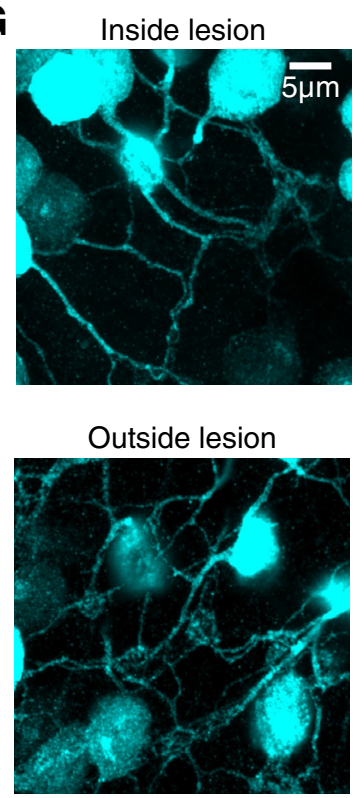

Figure 2. Bipolar cell dendritic trees change in response to photoreceptor loss. $A$, Dendritic tips of healthy rod bipolar cells (PKC $\alpha$, green) share a rod spherule with another rod bipolar cell, which is visible as a doublet structure (see insets) of the glutamate receptors (mGluR6, magenta). Rod bipolar cells lose their dendritic tips and glutamate receptors within $3 \mathrm{~d}$ of photoreceptor loss. Dendrite simplification and pruning are evident in 14-day-old lesions. Fine processes are lost, leaving only major dendritic branches (see cell on the left). Some cells show signs of asymmetric pruning (see cell on the right); dendrites directed toward a lesion edge (up) are strengthened compared with the dendritic branches directed toward the lesion center (down). $\boldsymbol{B}$, Dendrite pruning in rod bipolar cells of acute and older $200 \mu \mathrm{m}$ lesions in the same rabbit. Data are mean \pm SEM. C, Rod bipolar cells and glutamate receptors at the OPL of a 4-month-old $100 \mu \mathrm{m}$ lesion. $\boldsymbol{D}$, Inset from C. Dendritic tips are visible at the ends of the thickened rod bipolar cell dendrite (arrowheads). Dendritic tips colocalize with glutamate receptors and ribbons (CtBP2, cyan). $\boldsymbol{E}$, Projection angle and length of thickened dendrites from rod bipolar cells left (blue) and right (red) of lesion center. Lesion orientation is vertical, shown with black line. $\boldsymbol{F}$, Dendrites of secretagogin-positive cone bipolar cells in acute and older $200 \mu \mathrm{m}$ lesions in the same rabbit. These lesions are the same lesions as those in $\boldsymbol{B}$ and pictured in Figure $3 A$. $\boldsymbol{G}$, Cone bipolar cell (secretagogin, cyan) dendrites inside and outside a lesion. Small dendrites are still visible within the lesion, but their network appears abnormal.

structure in a preferred direction from the cell body (KolmogorovSmirnov test, $p>0.67$; Fig. 3D). Rod bipolar cell dendrites show significant bias to project out of the lesion at 2 and 4 months $(p<$ 0.01 ; Fig. $3 D$ ). Deafferented rod bipolar cells project their dendrites, including the thickened ones, toward the lesion edge, but deafferented secretagogin-positive cells do not form thickened dendrites and do not direct their dendrites toward the lesion edge.

Rod bipolar cells synapse with rods outside of their original dendritic territory

Two distinct mechanisms can result in the rod bipolar cells' thickened dendritic process extending toward healthy photoreceptors. First, the laser ablation could remove all but one photoreceptor input to the bipolar cell, leading to the removal of unoccupied synapses, pruning of the deafferented portion of the dendritic tree, and strengthening of the remaining functional dendrite. Alternatively, deafferented rod bipolar cells could restructure their dendrites to project into territory that has functional photoreceptors, where they can form new synapses.
To determine whether the rod bipolar cells extend their dendrites to form new synapses with healthy photoreceptors, we compared the dendritic reach of healthy rod bipolar cells with the reach of thickened dendrites found within lesioned retina. Because of the overlap of dendritic fields from PKC $\alpha$-positive cells, we could not discern the dendritic field of an individual healthy cell. Instead, we measured the dendritic reach of four healthy individually filled rod bipolar cells from mid-inferior rabbit retina (provided by Christopher Whitaker and Stephen Massey, cell-fill photographs not shown). For the filled cells, we measured the straight-line distance between each dendrite's exit from the soma and its distal termination at the edge of the dendritic field. These distances ( 32 dendrites from 4 cells) provided the distribution of the dendritic reach for the healthy rod bipolar cells (for details on the comparisons between PKC $\alpha$-positive cells and filled cells, see Materials and Methods).

The reach of the thickened dendritic processes of the deafferented rod bipolar cells is significantly (Kolmogorov-Smirnov test $p<1 \mathrm{E}-8)$ longer than that of healthy rod bipolar cells. Because 

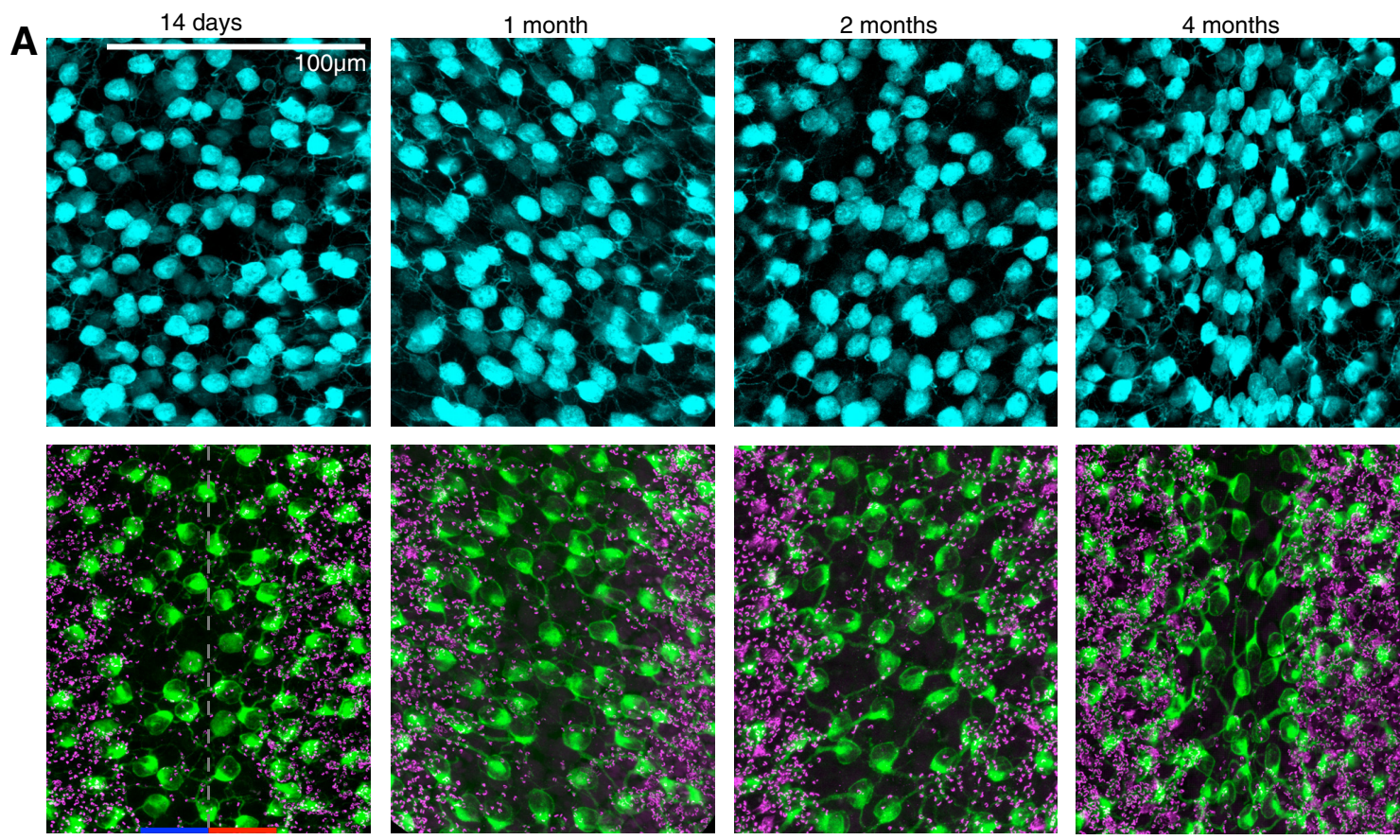

B
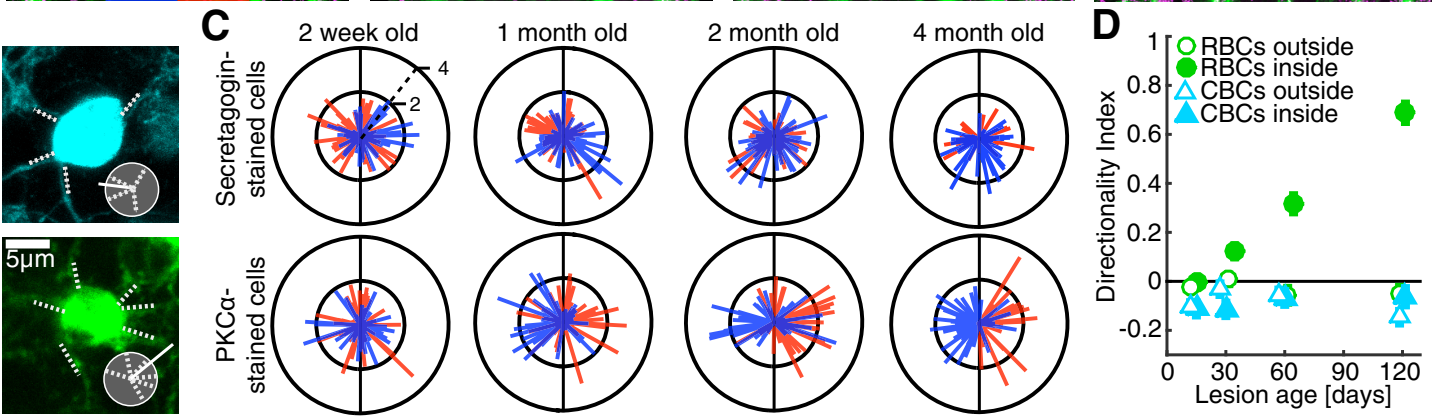

Figure 3. Rod and cone bipolar cells within the same lesion do not restructure their dendrites in the same manner. $A$, Cone bipolar cells (secretagogin, cyan) within $200 \mu \mathrm{m}$ lesions at $14 \mathrm{~d}, 1$ month, 2 months, and 4 months. Rod bipolar cells (PKC $\alpha$, green) in the same field of view as the cone bipolar cell images. Ribbons (CtBP2, magenta) in the rod bipolar images show lesion edges. $B$, Example vector sum calculations for a cone (secretagogin, cyan) and $\operatorname{rod}(\mathrm{PKC} \alpha$, green) bipolar cell. Measured dendrite projection angles (dashed white lines slightly offset from dendrites) are placed in a unit circle (gray circle) and summed to create a dendritic projection vector (solid white line) for each cell. $\boldsymbol{C}$, Dendritic projection vector sum analysis of the four lesions pictured in $\boldsymbol{A}$. Dendritic projection vectors representing all dendrites from cone and rod bipolar cells left (blue) and right (red) of lesion center. Lesion orientation is vertical, shown with a black line. $\boldsymbol{D}$, The directionality index of cone and rod bipolar cell dendrites inside or outside of a lesion. Rod bipolar cells (RBCs) inside 2- and 4-month-old lesions bias their dendrites to exit the lesion (KolmogorovSmirnov test, $p<0.01)$. Secretagogin-stained cone bipolar cells (CBCs) do not bias their dendrites to exit the lesion $(p>0.67)$.

the dendritic field size of rod bipolar cells changes with eccentricity (Young and Vaney, 1991), we wanted to ensure that the observed difference was not caused by comparing cells from different retinal locations. The significant $(p<0.01)$ difference between the reach of the restructured dendritic processes and that of the healthy dendrites remained, even after we scaled up the dendritic fields of the filled cells to reach the maximum reported rod bipolar cell dendritic field area of $1200 \mu \mathrm{m}^{2}$ (Young and Vaney, 1991) (Fig. 4A; for details of the scaling procedure, see Materials and Methods). This area corresponds to $10 \mathrm{~mm}$ eccentricity in the superior retina, which contains cells with dendritic fields larger than anywhere in the inferior retina, where lesions were actually placed.

The shift of the distribution toward longer dendritic reach is not simply a result of shorter dendrites being pruned away. We observe the increase in dendritic reach $(p<0.001)$, even in narrow lesions, where $98 \%$ of rod bipolar cells ( 49 of 50 cells) extend a thickened dendrite. Such a result cannot be achieved through a passive pruning process, unless all the original rod bipolar cell dendritic fields coincidentally had a longer reach in the direction perpendicular to the future lesion.
So far, we have not differentiated between rod bipolar cells that have been completely deafferented, restructured their dendrites, and formed new connections from rod bipolar cells that have been partially deafferented, and have extended their dendrites further into photoreceptor-rich areas to form new connections. We performed the following analysis to test whether some remaining synapses are necessary for the formation of new synapses. If only partially deafferented rod bipolar cells are capable of synaptogenesis, then the original dendritic reach of a restructured rod bipolar cell is determined by the dendritic reach distribution of healthy cells. Under this hypothesis, we estimated the minimum original dendritic reach of the restructured cells to be the distance from the cell body to the first synapse located on the restructured thick dendrite. In healthy rod bipolar cells, 0 of 32 dendrites reach beyond $28 \mu \mathrm{m}$ from the cell body (from four filled cells with dendritic fields scaled up to emulate cells in the far peripheral retina, see Materials and Methods). At the same time, in a 4-month-old, 300- $\mu$ m-wide lesion, 6 of the 41 rod bipolar cells located $28 \mu \mathrm{m}$ or farther from the nearest photoreceptor synaptic ribbon extended a dendrite that could be traced to a synaptic contact. The two results do not come from the same 

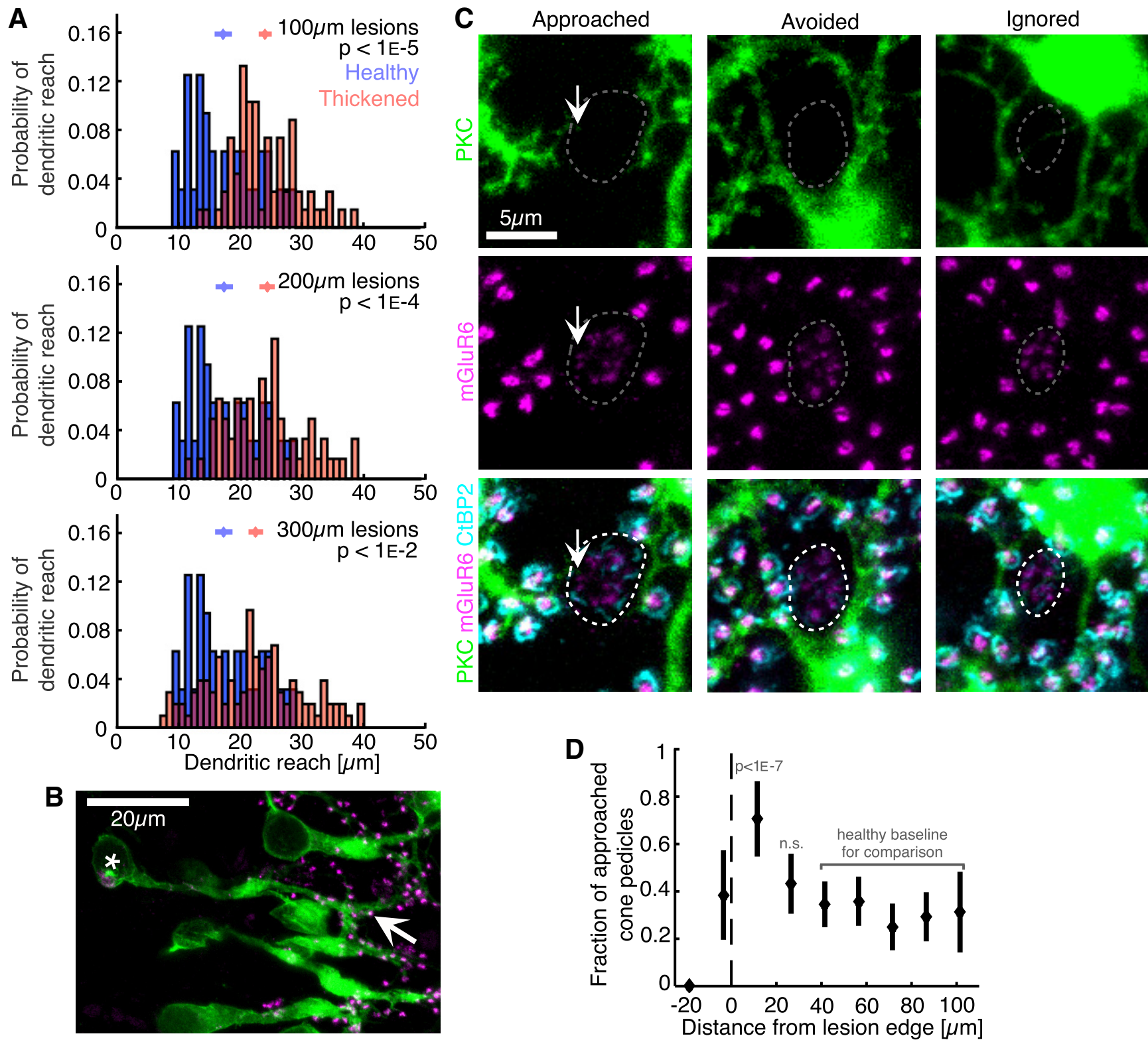

Figure 4. Rod bipolar cells actively search for new synaptic partners. $\boldsymbol{A}$, The dendritic reach of healthy rod bipolar cell dendrites (blue) and thickened dendrites (red) in 100, 200 , and $300 \mu \mathrm{m}$ lesions. Data are mean \pm SEM (shown above the two populations). $p$ values from the Kolmogorov-Smirnov test are printed for each lesion size. $\boldsymbol{B}$, Example rod bipolar cell $\left({ }^{*}\right)$ in a lesion with a 45 $\mu \mathrm{m}$ dendritic reach making synaptic contact outside the lesion, shown by an mGluR6 doublet located distally on the dendrite (arrow). C, Examples of cone pedicles (outlined by dashed shape) being approached, avoided, or ignored by a rod bipolar cell dendrite. Typically, rod bipolar cell dendritic tips (PKC $\alpha$, green) terminate at rod spherules (mGluR6 doublets, bright magenta outside dashed shape). Occasionally, a rod bipolar cell dendritic tip terminates within a cone pedicle (arrow). $\boldsymbol{D}$, Fraction of cone pedicles that are approached by a rod bipolar cell dendrite. Fractions are given as mean \pm SEM. $p$ values are calculated using unpooled binomial statistics.

distribution ( $p=0.03$ using binomial statistics; see Materials and Methods), indicating that some of the rod bipolar cells with long restructured dendrites were completely deafferented and then formed new synapses with healthy photoreceptors.

These findings, combined with synaptic contacts found at the extremities of all the lengthened dendrites we could trace (Fig. $4 B$ ), show that rod bipolar cells in the adult rabbit retina are capable of sending dendritic projections well beyond their original dendritic field territory to synapse with rod photoreceptors.

Next, we asked whether the dendrites of deafferented rod bipolar cells selectively target rod photoreceptors or whether they approach cone pedicles as well. Cone pedicles can be distinguished from rod spherule synaptic contacts by differences in the mGluR6 expression pattern and ribbon synapse structure (Li et al., 2004); rod spherules are marked by bright mGluR6 doublets and bright horseshoe-shaped ribbons, whereas cone pedicles appear as small clusters of mGluR6 puncta and dimmer clustered ribbons (cone pedicles outlined by dashed shape, Fig. $4 C$ ). To determine whether rod bipolar cells selectively target rod photoreceptors after deafferentation, we measured the frequency of a cone pedicle being approached, rather than bypassed by a rod bipolar cell dendrite as a function of cone location relative to the lesion edge. Cone pedicles were bypassed by rod bipolar dendrites in one of two possible ways: avoided or ignored (for details on approached, avoided, and ignored labels, see Materials and Methods; for examples, see Fig. 4C). We find that cone pedicles just outside the lesion edge are significantly more likely to be approached than bypassed by a rod bipolar cell dendrite com- 

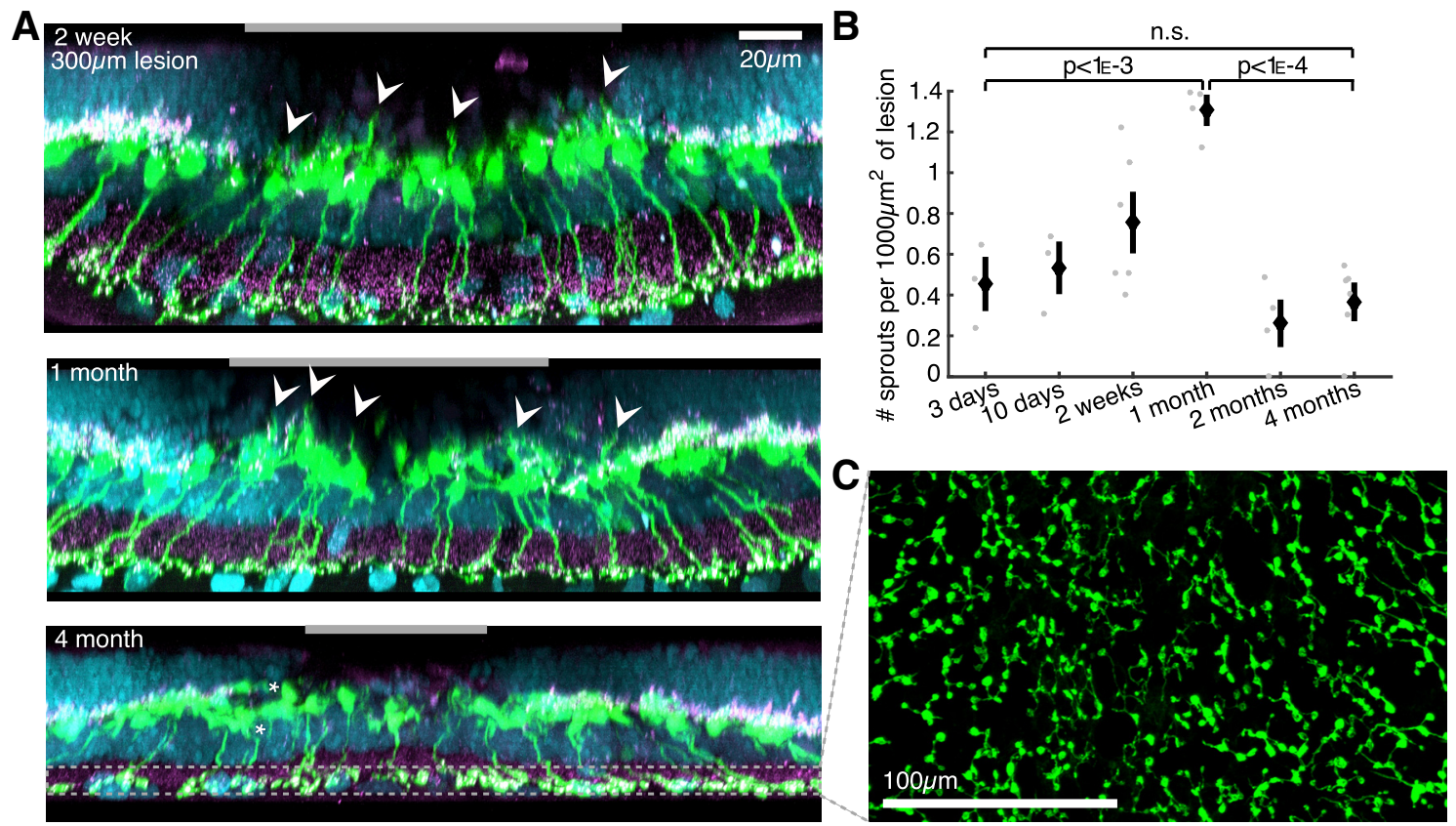

Figure 5. Sprouting, but not cell body movement, is reversed in recovering lesions. A, Cross sections of confocal z stacks of 2-week-, 1-month-, and 4-month-old lesions. Green represents rod bipolar cells (PKC $\alpha$ ). Magenta represents ribbons (CtBP2). Cyan represents nuclei of the retinal neural cells labeled with DAPI. Rod bipolar cells have axons and axon terminals at all lesion ages. Dendritic sprouts (arrows) are common in 2-week- and 1-month-old lesions, but not present at 4 months. In the 4-month-old lesion, asterisks indicate two example cells that have moved vertically (up and down) out of their normal layer. Horizontal gray bars represent width of ONL missing (DAPI stained) photoreceptor cell bodies. Variation in retinal thickness between these cross sections results from variable squashing of the tissue during electrophysiological recording. $\boldsymbol{B}$, The frequency of sprouting rod bipolar cells in $300 \mu \mathrm{m}$ lesions (gray dots) over time. Data are mean \pm SEM. $p$ values (Student's $t$ test). C, Axon terminals of rod bipolar cells within a 4-month-old lesion, viewed as a maximal $z$ projection, as indicated by the dashed box in $\boldsymbol{A}$.

pared with cone pedicles in the intact healthy areas $(p<1 \mathrm{E}-7$, using unpooled binomial statistics based on 298 cones) (Fig. 4D). We do not have the necessary resolution to determine whether the rod bipolar cell dendrites that terminate within a cone pedicle make synaptic contact with the cone. Thus, these data suggest that either the adult deafferented rod bipolar cell dendrites are less selective in choosing synaptic partners or they explore potential afferents before making contact. Interestingly, of the 112 approached cone pedicles, only 2 were approached by more than one rod bipolar cell dendrite.

\section{New synaptic partners for deafferented rod bipolar cells reverse sprouting}

Photoreceptor damage or disease often leads to dramatic changes in retinal structure. In response to photoreceptor malfunction, bipolar cells send dendritic sprouts into the outer nuclear layer (ONL) that can sometimes result in ectopic synapses (Haverkamp et al., 2006; Sullivan et al., 2007). In our injury model, rod bipolar cells also exhibit initial sprouting and ectopic synapses in the ONL (Fig. $5 A$, arrowheads); however, they decrease over time (Figs. $5 A, B$ ). This observation indicates that, if provided with healthy presynaptic partners, rod bipolar cells will prune "incorrect" sprouts in the ONL in favor of making contacts with rods in the OPL.

Axon terminal atrophy is also commonly reported in animal models of retinal degeneration (Strettoi and Pignatelli, 2000; Strettoi et al., 2003; Barhoum et al., 2008). Deafferented rod bipolar cells with restructured dendrites maintain their axons and terminals in the ON inner plexiform layer (Fig. 5A). Axon terminals are not disfigured and retain coverage of the inner plexiform layer (Fig. 5C).

We find that rod bipolar cell somas within the lesion area can move vertically toward the ONL or deeper into the INL (Fig. 5A). Cell soma movement out of their original layer is known to occur during advanced stages of retinal degeneration (Jones and Marc, 2005). Here we observed cellular displacement at a much smaller scale: $<20 \%$ of cells within the 4 -month-old $300 \mu \mathrm{m}$ lesion pictured in Figure $5 A$ appear vertically displaced $(n=29$ of 176 cells). We observed similar displacements in 4-month-old lesions of all initial widths. The lateral shift of the rod bipolar cell bodies, indicated by their axons angled toward the lesion center (Fig. 5A) and manifested by higher density of bipolar cell soma within 4-month-old lesions (Fig. 3A), is probably caused by wound contraction.

\section{Discussion}

This study demonstrates synaptogenesis in the adult mammalian retina that recovers the flow of visual information through both scotopic and photopic circuitry. After a patch of photoreceptors is selectively destroyed by laser photocoagulation, healthy photoreceptors and their synaptic terminals surrounding the lesion shift laterally into the damaged zone. Visual sensitivity is restored in the previously blinded areas at both scotopic and photopic light levels. Rod bipolar cells drastically prune and restructure their dendritic tree and synapse with healthy rod photoreceptors. In contrast, cone bipolar cells maintain their primary dendrites and do not bias their dendritic fields toward remaining photoreceptors. Sprouting of rod bipolar cell dendrites, an early sign of retinal degeneration, is reversed in favor of new rod afferents. These observations demonstrate an innate ability of the adult mammalian retina to repair damage caused by injury or disease and is encouraging for the photoreceptor reintroduction approach to restoration of sight.

Adult rod bipolar cells are capable of normal synaptogenesis Examination of the functional and structural dynamics of rod and cone photoreceptors, their synapses, and their postsynaptic 
partners after ablation of photoreceptors reveals the following processes: initial loss of the photoreceptor outer segments, cell bodies, and ribbon synapses matched on the postsynaptic side with a disappearance of mGluR6 in the dendrites of rod bipolar cells, which complements findings from a report on mouse cone bipolar cells (Dunn, 2015). By 4 months, both rods and cones from adjacent areas have shifted into the lesion along with their synaptic terminals, creating new synaptic opportunities inside the lesioned area. Rod bipolar cell dendrites extend out of the lesioned space, supporting the hypothesis that shifting photoreceptors are making new contacts rather than simply dragging old contacts with them (Fig. 2E) (Sher et al., 2013). Synapses near the lesion appear structurally normal and are indistinguishable from synapses in the intact areas. Restoration of visual sensitivity in the former blind spot over time indicates that these shifting synapses are functional, both at the cone pedicle and rod spherule.

A new synaptic contact between a rod and rod bipolar cell is not limited by proximity; rod bipolar cells project dendrites over long distances to form new connections. This projection is directed to the nearest edge of the lesion, suggesting that some signal from the healthy photoreceptors is guiding the dendrites. These dendrites approach cone pedicles in addition to rod spherules. Some of these approaches may result in a cone to rod bipolar cell synapse, which is known to occur in both the healthy and diseased retina (Dacheux and Raviola, 1986; Peng et al., 2000; Strettoi et al., 2004). However, in diseased retina, cone to rod bipolar cell synapses were shown to occur more frequently than in healthy retina (Peng et al., 2000). We also observed an increase in such approach events at the lesion edge, indicating that, although deafferented adult rod bipolar cells form new synapses with rods, they may also synapse with cone photoreceptors.

\section{Rod and cone pathways differ in their plasticity}

We observed dramatic dendritic rearrangements of the deafferented rod bipolar cells, but secretagogin-positive cone bipolar cell dendrites did not restructure in the same manner. Deafferented secretagogin-positive cells maintain the number of their primary dendrites and do not project their processes out of the lesion. We did note that secretegogin-positive cone bipolar cell dendrites had, on average, a small negative directionality index, indicating that the dendritic trees are slightly biased toward the center of the lesions (Fig. 3D). This bias is already present at $14 \mathrm{~d}$ in both deafferented cells within and unaffected cells outside the lesion; it is likely caused by wound contraction after photocoagulation, wherein tissue is pulled toward the lesion center. This pull is evident in the leaning of the rod bipolar cell axons toward the lesion center (Fig. 5A).

Imaging of the secretagogin-positive bipolar cells did not allow us to ascertain whether the deafferented cone bipolar cells form new synapses with the shifted photoreceptors. Both photopic and scotopic vision is partially restored after photoreceptor ablation, indicating that the shifting photoreceptors have functional synapses. Previous work revealed that cone bipolar cells, as a population, regain light sensitivity after deafferentation, indicating that some synaptogenesis has occurred (Sher et al., 2013). Secretagogin-positive bipolar cells are only a subset of that population. Studies of additional cone bipolar cell types are needed to better understand the response to deafferentation within the cone pathway.

Variations in dendritic restructuring between the rod and secretagogin-positive cone bipolar cells demonstrate that there are different cellular level mechanisms behind the response to deafferentation and restoration of function in rod and cone cir- cuits. The difference in the mechanisms of adult rod and cone bipolar cells rewiring to their new presynaptic partners is not necessarily a surprise. It has been reported that three cone bipolar cell types within the developing mouse retina find and establish cone contacts using unique strategies (Dunn and Wong, 2012). It has also been shown that the underlying molecular mechanisms required for proper connectivity between photoreceptors and bipolar cells during development differ between the rod and cone pathways (Cao et al., 2015). Identifying the molecular mechanisms behind the dendritic expansion and synaptogenesis in the adult retina requires further work.

\section{Sprouting may be reversible if photoreceptors become available}

Dendritic sprouting into inappropriate locations is an early response to retinal degeneration triggered by photoreceptor cell death (Marc et al., 2003). The human retina has been shown to exhibit sprouting of rod bipolar cell dendrites and ectopic synapses in the outer nuclear layer in response to local loss of photoreceptors during age-related macular degeneration (Sullivan et al., 2007). Similarly, the rod bipolar cell dendrites in the adult rabbit retina sprout into the outer nuclear layer after loss of photoreceptors, and occasionally make ectopic synapses. We find that dendrites sprouting into the outer nuclear layer are abandoned in favor of new contacts in the OPL. New presynaptic partners may eliminate this particular unwanted plastic response.

\section{Implications for vision restoration in humans}

The results of this study provide new insight into the capability of the adult mammalian retina to form synapses with new afferents, and show the differences between bipolar cell types regarding this capability. However, it is important to recognize that the restructuring we describe here may differ across species. For example, in the primate (including human) retina, each midget bipolar cell contacts a single-cone photoreceptor in the fovea region, providing high visual acuity. Therefore, the midget bipolar cells constitute the vast majority of bipolar cells in the central primate retina. Given the differences we observe between the rod and secretagogin-positive cone bipolar cell dendritic restructuring in the rabbit retina, it is hard to predict how well primate midget bipolar cells will connect to newly introduced photoreceptors. Future studies will need to address this important question.

Because the surrounding healthy photoreceptors in our experiments were already connected to the retina, it remains unknown whether these preexisting connections with postsynaptic partners facilitated or hindered synaptogenesis with the deafferented rod bipolar cells. This is one of many potential factors that might affect the success of photoreceptor reintroduction into degenerate retina.

Another factor that is likely to affect the success of photoreceptor reintroduction is its timing relative to the degeneration progression. The chances of success in restoring proper retinal wiring are likely to diminish after the complete loss of photoreceptors due to the movement of ganglion cells and the formation of aberrant connections occurring at this late stage (Jones and Marc, 2005; Jones et al., 2012). Our findings suggest that partially and completely deafferented rod bipolar cells, which are both likely present before the complete loss of photoreceptors, will be able to recruit new presynaptic partners in the event of successful photoreceptor reintroduction earlier in disease progression. 


\section{Bipolar cells, not photoreceptors, find new synaptic partners} The success of photoreceptor reintroduction therapies critically depends on the ability of the deafferented bipolar cells to establish synapses with the new photoreceptors. Our results indicate that the adult mammalian retina is capable of establishing new functional connections between bipolar cells and photoreceptors. We show that, in the rod pathway, it is the rod bipolar cells rather than photoreceptors that prompt synaptogenesis. Dramatic changes in the rod bipolar cell dendrites contrasts with the lack of restructuring in the cone bipolar cells. These differences show that various mechanisms for synaptogenesis operate separately within different bipolar cell types after deafferentation. Deciphering these mechanisms will advance the effort to restore vision in degenerating retinas.

\section{References}

Barhoum R, Martínez-Navarrete G, Corrochano S, Germain F, FernandezSanchez L, de la Rosa EJ, de la Villa P, Cuenca N (2008) Functional and structural modifications during retinal degeneration in the rd10 mouse. Neuroscience 155:698-713. CrossRef Medline

Busch EM, Gorgels TG, Van Norren D (1999) Filling-in after focal loss of photoreceptors in rat retina. Exp Eye Res 68:485-492. CrossRef Medline

Cao Y, Sarria I, Fehlhaber KE, Kamasawa N, Orlandi C, James KN, Hazen JL, Gardner MR, Farzan M, Lee A, Baker S, Baldwin K, Sampath AP, Martemyanov KA (2015) Mechanism for selective synaptic wiring of rod photoreceptors into the retinal circuitry and its role in vision. Neuron 87: 1248-1260. CrossRef Medline

Chichilnisky EJ (2001) A simple white noise analysis of neuronal light responses. Network 12:199-213. Medline

Dacheux RF, Raviola E (1986) The rod pathway in the rabbit retina: a depolarizing bipolar and amacrine cell. J Neurosci 6:331-345. Medline

D’Orazi FD, Suzuki SC, Wong RO (2014) Neuronal remodeling in retinal circuit assembly, disassembly, and reassembly. Trends Neurosci 37:594603. CrossRef Medline

Dunn FA (2015) Photoreceptor ablation initiates the immediate loss of glutamate receptors in postsynaptic bipolar cells in retina. J Neurosci 35: 2423-2431. CrossRef Medline

Dunn FA, Wong RO (2012) Diverse strategies engaged in establishing stereotypic wiring patterns among neurons sharing a common input at the visual system's first synapse. J Neurosci 32:10306-10317. CrossRef Medline

Field GD, Sher A, Gauthier JL, Greschner M, Shlens J, Litke AM, Chichilnisky EJ (2007) Spatial properties and functional organization of small bistratified ganglion cells in primate retina. J Neurosci 27:13261-13272. CrossRef Medline

Haverkamp S, Michalakis S, Claes E, Seeliger MW, Humphries P, Biel M, Feigenspan A (2006) Synaptic plasticity in CNGA3(-/-) mice: cone bipolar cells react on the missing cone input and form ectopic synapses with rods. J Neurosci 26:5248-5255. CrossRef Medline

Jones BW, Marc RE (2005) Retinal remodeling during retinal degeneration. Exp Eye Res 81:123-137. CrossRef Medline

Jones BW, Kondo M, Terasaki H, Lin Y, McCall M, Marc RE (2012) Retinal remodeling. Jpn J Ophthalmol 56:289-306. CrossRef Medline

Lavinsky D, Cardillo JA, Mandel Y, Huie P, Melo LA, Farah ME, Belfort R, Palanker D (2013) Restoration of retinal morphology and residual scarring after photocoagulation. Acta Ophthalmol 91:e315-e323. CrossRef Medline

Li W, Keung JW, Massey SC (2004) Direct synaptic connections between rods and OFF cone bipolar cells in the rabbit retina. J Comp Neurol 474:1-12. CrossRef Medline

Litke A, Bezayiff N, Chichilnisky EJ, Sher A (2004) What does the eye tell the brain? Development of a system for the large-scale recording of retinal output activity. Nucl Sci 51:1434-1440. CrossRef
Lorach H, Kung J, Beier C, Mandel Y, Dalal R, Huie P, Wang J, Lee S, Sher A, Jones BW, Palanker D (2015) Development of animal models of local retinal degeneration. Invest Ophthalmol Vis Sci 56:4644-4652. CrossRef Medline

MacLaren RE, Pearson RA, MacNeil A, Douglas RH, Salt TE, Akimoto M, Swaroop A, Sowden JC, Ali RR (2006) Retinal repair by transplantation of photoreceptor precursors. Nature 444:203-207. CrossRef Medline

Marc RE, Jones BW, Watt CB, Strettoi E (2003) Neural remodeling in retinal degeneration. Prog Retin Eye Res 22:607-655. CrossRef Medline

Pan F, Massey SC (2007) Rod and cone input to horizontal cells. J Comp Neurol 500:815-831. CrossRef Medline

Paulus YM, Jain A, Gariano RF, Stanzel BV, Marmor M, Blumenkranz MS, Palanker D (2008) Healing of retinal photocoagulation lesions. Invest Ophthalmol Vis Sci 49:5540-5545. CrossRef Medline

Paulus YM, Jain A, Nomoto H, Sramek C, Gariano RF, Andersen D, Schuele G, Leung LS, Leng T, Palanker D (2011) Selective retinal therapy with microsecond exposures using a continuous line scanning laser. Retina 31:380-388. CrossRef Medline

Pearson RA (2014) Advances in repairing the degenerate retina by rod photoreceptor transplantation. Biotechnol Adv 32:485-491. CrossRef Medline

Peng YW, Hao Y, Petters RM, Wong F (2000) Ectopic synaptogenesis in the mammalian retina caused by rod photoreceptor-specific mutations. Nat Neurosci 3:1121-1127. CrossRef Medline

Puthussery T, Gayet-Primo J, Taylor WR (2010) Localization of the calcium-binding protein secretagogin in cone bipolar cells of the mammalian retina. J Comp Neurol 518:513-525. CrossRef Medline

Sher A, DeVries SH (2012) A non-canonical pathway for mammalian bluegreen color vision. Nat Neurosci 15:952-953. CrossRef Medline

Sher A, Jones BW, Huie P, Paulus YM, Lavinsky D, Leung LS, Nomoto H, Beier C, Marc RE, Palanker D (2013) Restoration of retinal structure and function after selective photocoagulation. J Neurosci 33:6800-6808. CrossRef Medline

Singh MS, MacLaren RE (2011) Stem cells as a therapeutic tool for the blind: biology and future prospects. Proc Biol Sci 278:3009-3016. CrossRef Medline

Stasheff SF, Shankar M, Andrews MP (2011) Developmental time course distinguishes changes in spontaneous and light-evoked retinal ganglion cell activity in $\mathrm{rd} 1$ and $\mathrm{rd} 10$ mice. J Neurophysiol 105:3002-3009. CrossRef Medline

Strazzeri JM, Hunter JJ, Masella BD, Yin L, Fischer WS, DiLoreto DA, Libby RT, Williams DR, Merigan WH (2014) Focal damage to macaque photoreceptors produces persistent visual loss. Exp Eye Res 119:88-96. CrossRef Medline

Strettoi E, Pignatelli V (2000) Modifications of retinal neurons in a mouse model of retinitis pigmentosa. Proc Natl Acad Sci U S A 97:11020-11025. CrossRef Medline

Strettoi E, Pignatelli V, Rossi C, Porciatti V, Falsini B (2003) Remodeling of second-order neurons in the retina of $\mathrm{rd} / \mathrm{rd}$ mutant mice. Vision Res 43:867-877. CrossRef Medline

Strettoi E, Mears AJ, Swaroop A (2004) Recruitment of the rod pathway by cones in the absence of rods. J Neurosci 24:7576-7582. CrossRef Medline

Sullivan RK, Woldemussie E, Pow DV (2007) Dendritic and synaptic plasticity of neurons in the human age-related macular degeneration retina. Invest Ophthalmol Vis Sci 48:2782-2791. CrossRef Medline

tom Dieck S, Altrock WD, Kessels MM, Qualmann B, Regus H, Brauner D, Fejtová A, Bracko O, Gundelfinger ED, Brandstätter JH (2005) Molecular dissection of the photoreceptor ribbon synapse: physical interaction of Bassoon and RIBEYE is essential for the assembly of the ribbon complex. J Cell Biol 168:825-836. CrossRef Medline

Vardi N, Duvoisin R, Wu G, Sterling P (2000) Localization of mGluR6 to dendrites of ON bipolar cells in primate retina. J Comp Neurol 423:402412. CrossRef Medline

Young HM, Vaney DI (1991) Rod-signal interneurons in the rabbit retina: 1. Rod bipolar cells. J Comp Neurol 310:139-153. CrossRef Medline 